\title{
Cardiovascular Diseases in Dhulikhel Hospital
}

\section{Koju R, Dangol S, Pokharel A, Karmacharya B, Takhacche S}

Dhulikhel Hospital is a non-profit community hospital located in Dhulikhel, $30 \mathrm{~km}$ east of Kathmandu, providing services to Kavrepalanchowk and other surrounding districts of nearly 1.2 million people since 1996. The hospital is providing services of medical, surgical, obstetric and gynecological, pediatric and other services.

In 2003, total number of Outpatients was 33716 and in patients was 3220 . Among the outdoor Patients, patients with cardiovascular disease were 728 , in which 174 were new and 554 were old. Among admitted patients, out of 1130 medical cases, 128 were cardiac patients. It was $11.33 \%$ of total medical admission with male $(n=58)$, female $(n=70)$ ratio of 0.83:1, Corpulmonale (28.13\%). Rheumatic Heart Disease (17.97\%), and Ischemic Heart Disease (16.41\%) were the common cardiovascular diseases, admitted in 2003, Besides these, Hypertension $-14, .84 \%$, Cardiomyopathies $-7.81 \%$, Congestive Cardiac Failure $5.47 \%$ were others in the list. There were total 23 cases of Rheumalic heart disease with male female ratio of $0.35: 1$. Rheumatic heart disease was common in the age group of 1120 years, whereas Ischemic heart disease in 51-60 years and hypertension in 41-50 years. All cases of Corpulmonale were found with chronic obstructive pulmonary diseases.

The mean age of cardiac inpatients was $45.61 \pm 18.95$ years. The average duration of stay in hospital admission was 6.7 days. $65 \%$ of admitted cardiac patients were from Kavrepalanchowk district, 16\% from Sindhupalchowk and rest from other districts. 